Año LXXXI. urtea $276-2020$ Enero-abril Urtarrila-apirila

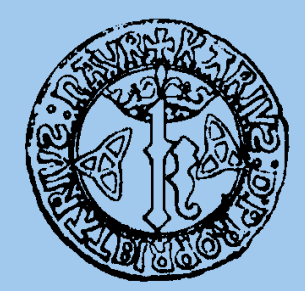

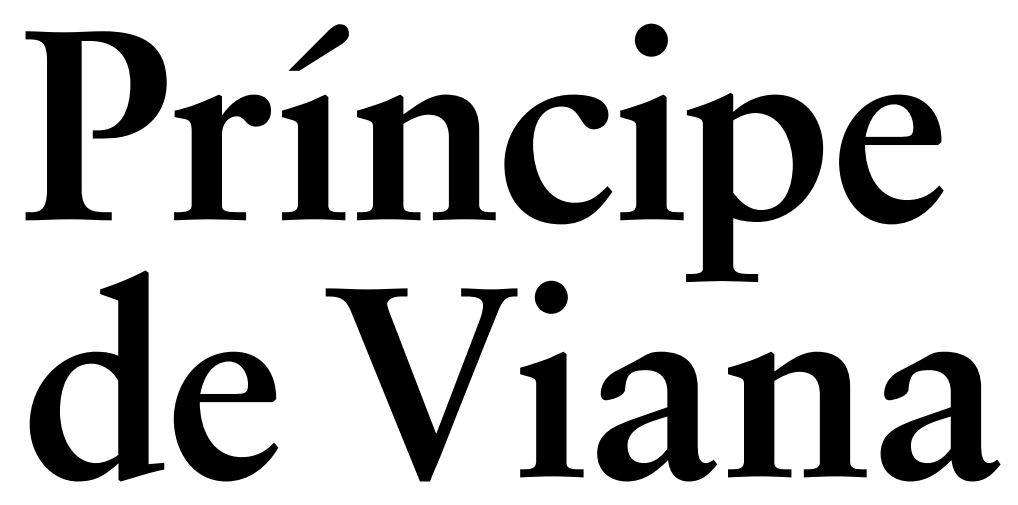

SEPARATA

Entrevista a Tomás Yerro Villanueva

Premio Príncipe de Viana de la Cultura 2019

Alicia Ezker Calvo 


\section{Sumario / Aurkibidea}

\section{Príncipe de Viana}

Año LXXXI • n. ${ }^{\circ} 276$ • enero-abril de 2020

LXXXI. urtea $\cdot 276$. zk. 2020 ko urtarrila-apirila

\section{LITERATURA}

La realidad literaturizada y la ira contra la religión católica y el obispo de Pamplona en el «Libro segundo» de La familia de Errotacho, de Pío Baroja Miguel Ángel García de Juan

\section{HISTORIA}

La represión del protestantismo en el tribunal inquisitorial de Calahorra-Logroño (1550-1610)

Marcos Gómez García

Entre España y México, la libertad. El embajador Félix Gordón Ordás y su evocación de la figura del navarro Javier Mina en el marco de la guerra civil española

Un discurso inédito de Víctor Sainz de Robles en 1867

Emilio Cervantes Ruiz de la Torre

Política social y autogobierno en el núcleo de la conspiración carlista antirrepublicana

La botica del monasterio cisterciense de Santa María de La Oliva (Navarra) Juan Manuel Garde Garde

\section{DERECHO / ZUZENBIDEA}

Un debate sobre la Ley de 1841: Navascués, la Diputación, «El Mosquerino» y Ezquerra 


\section{Sumario / Aurkibidea}

\section{LOS TRABAJOS Y LOS DÍAS DEL AÑO 2019 / 2019ko LANAK ETA EGUNAK}

Tesis doctorales sobre temática navarra de ciencias humanas, sociales y jurídicas, leídas en 2019

(Según la Base de datos Teseo del Ministerio de Educación)

Medio siglo de Fontes Linguae Vasconum

Ekaitz Santazilia

Actividades en torno al cincuenta aniversario de la revista Cuadernos de

Etnología y Etnografía de Navarra

David Mariezkurrena

Autores y autoras navarras en castellano, año 2019

Mikel Zuza Viniegra

Nafar egileen euskarazko liburuak 2019an

Ángel Erro Jiménez

Viento a favor: talento y carácter. Navarra en la industria audiovisual (2019)

Marga Gutiérrez Díez

Tensión de rotura. Un panorama expositivo de 2019

Mireya Martín Larumbe

Hiriartea: crónica de un proyecto frustrado por una mala práctica en las políticas culturales

Arantza Santesteban

De escalas, tiempos y cultura: grado en Historia y Patrimonio por la UPNA

Fernando Mendiola Gonzalo, Miguel R. Wilhelmi

Investigación y difusión del patrimonio cultural navarro en la Universidad de

Navarra (2019)

Yolanda Cagigas Ocejo

Entrevista a Tomás Yerro Villanueva. Premio Príncipe de Viana de la Cultura 2019

Alicia Ezker Calvo

Si mi padre volviera, yo sería su escudero. Qué gran caballero era

Tomás Yerro. (Discurso)

Currículums

Analytic Summary

Normas para la presentación de originales / Idazlanak aurkezteko arauak /

Rules for the submission of originals

6 Príncipe de Viana (PV), 276, urtarrila-apirila, 2020 ISSN: 0032-8472 | ISSN-e: 2530-5824 | ISSN-L: 0032-8472 


\title{
Entrevista a Tomás Yerro Villanueva
}

\section{Premio Príncipe de Viana de la Cultura 2019}

\author{
Alicia EZKer CALvo \\ Periodista \\ aliezker@gmail.com
}

DOI: https://doi.org/10.35462/pv.276.18

Tomás Yerro Villanueva es un hombre de palabra y de palabras. Escritor, profesor, investigador, amante de la literatura y la cultura, de la conversación y de las buenas relaciones entre las personas. Siempre con un libro en las manos o al menos en la mente, pero con los pies en las raíces de Lerín y su familia. Siempre dispuesto a colaborar donde se le reclama, generoso y comprometido. Tomás Yerro nació en Lerín (Navarra) en 1950, el segundo de cuatro hermanos, todos varones. Desde 1974 está casado con María José Vela Pons, catedrática de Lengua y Literatura Española de Enseñanza Media. Tienen dos hijas, Irene, arquitecta, y Ana, periodista, y cuatro nietos -Luna, Leo, Lorenzo y Alicia-. Su trayectoria académica le llevó en 2019 a formar parte de la lista de personas merecedoras del Premio Príncipe de Viana de la Cultura, un galardón que en su caso reconocía según el Consejo Navarro de Cultura, entidad que propone al premiado, «su labor en tres ámbitos, como docente, como investigador y como promotor y divulgador de la literatura, especialmente entre los colectivos vulnerables» al tiempo que le considera todo «un referente» para las y los escritores navarros. De hecho, su candidatura fue presentada y defendida por la Asociación Navarra de Escritores/as-Nafar Idazleen Elkartea. Ahora, un año después del premio sigue volcado en su recuperación de una grave enfermedad y refugiado en los libros y la familia.

Esta entrevista se ha demorado más de la cuenta. Entre otras cosas por el momento tan extraordinario en el que nos encontramos, en esta inolvidable primavera de 2020, en estado de alarma ante la grave crisis sanitaria por la pandemia del Covid 19. Antes de nada me gustaría preguntarle cómo se encuentra y cómo ha llevado el confinamiento y toda esta situación tan excepcional. ¿Ha estado escribiendo?

Me he adaptado sin mayores dificultades al confinamiento a causa de mi temperamento estoico, a las muchas horas de mi vida encerrado en casa y dedicado a la lectura 
y la escritura y, sobre todo, al aprendizaje desarrollado durante mi proceso clínico, iniciado en marzo de 2017. Al recibir el grave diagnóstico experimenté los mismos sentimientos que las personas, a título individual y colectivo, están descubriendo o padeciendo durante el estado de alarma: conciencia de vulnerabilidad e interdependencia, gratitud (en especial hacia el personal sanitario), valoración de los trabajos en verdad esenciales, incertidumbre, desasosiego, angustia, miedo... Lo diré con toda humildad: en cierto modo estaba ya vacunado e inmunizado para afrontar con notables garantías de éxito una situación tan excepcional y crítica como la que en la actualidad afecta a todo el mundo. Los primeros días no estaba preparado para recibir tal aluvión de noticias y comentarios procedentes de los medios, que a la postre, por saturación, se convertían en desinformación. Con el correr del calendario, logré liberarme de ese agobio.

Me he dedicado principalmente a leer, más bien a releer, y escribir y también a escuchar música y ver, una vez más, algunas de las películas que han hecho historia, sin descuidar la comunicación permanente con familiares, amigos y colegas.

Como dice usted ya estaba pasando por una situación de salud delicada, con tratamiento por un cáncer. ¿Cómo está, se ha sentido más vulnerable en este momento? ¿Quizás con más miedo, un miedo general por otro lado en gran parte de la sociedad?

De momento la quimioterapia está consiguiendo estabilizar la dolencia y, además, con leves o inexistentes efectos secundarios, lo cual me permite seguir cultivando un régimen de vida muy normalizado. Soy consciente de ser un superviviente, de estar viviendo casi de propina gracias a la labor encomiable del personal sanitario y a la compañía, ayuda y apoyo de mis familiares y amigos íntimos, algunos forjados en las dependencias del hospital de día de Oncología del Complejo Hospitalario de Navarra. En esta tesitura de fragilidad suma, solo cabe practicar un carpe diem sin estridencias, fruto de una depuración de la escala de valores personales y sociales. O lo que es lo mismo, saborear a fondo el amor, la paternidad, la abuelidad, la amistad...; disfrutar de la belleza en todas sus manifestaciones, sobre todo las de índole cultural y artística, y, cómo no, valorar como nunca la naturaleza. Recuerde que procedo de familia de campesinos. Se trata de vivir con gozo el día a día paladeando las cosas pequeñas, aquellas que, casi sin darnos cuenta, nos acercan a la dicha, palabra que prefiero a felicidad, que considero demasiado solemne y pretenciosa. La enfermedad contribuye, qué duda cabe, a distinguir las voces de los ecos, que diría don Antonio Machado, lo importante de lo secundario.

Por pertenecer a un grupo de algo riesgo ante el Covid-19 en razón de la edad y de mi condición de paciente oncológico, he adoptado todas las medidas protectoras establecidas por las autoridades sanitarias y alguna más recomendada por mi oncóloga. Sin embargo, no he sentido el miedo ante el futuro y en particular ante la muerte por los motivos apuntados antes. Es más, algunos familiares y amigos, preocupadísimos por mi estado de salud, se han sorprendido al verme tan sereno como siempre en las actuales circunstancias. Les he tenido que explicar el porqué. Lo que más me ha afectado durante estas semanas ha sido el final en soledad de tantos miles de ancianos en condiciones deplorables, indignas, y el plus de desconsuelo de sus seres queridos. Por haber estado 
muy implicado como voluntario durante no pocos años en la Sociedad Navarra de Geriatría y Gerontología (SNGG) y en varias residencias de ancianos, me ha resultado imposible sustraerme a esta tragedia en términos intelectuales y afectivos. Desde diciembre de 2016, en la SNGG coordino el grupo de investigación interdisciplinar dedicado a estudiar y atenuar en lo posible la soledad de los ancianos, otra de las pandemias del estado de bienestar. Recuerdo ahora que el 11 de diciembre de 2019 mantuve un debate público sobre esta materia con Yolanda Liberal, psicóloga de la Casa de Misericordia de Pamplona, precisamente en el salón de actos de La Meca y con asistencia de cuidadores procedentes de diferentes geriátricos de Navarra y residentes del propio centro. Nunca pude imaginar que la soledad pudiera revestir tal grado de intensidad y precisamente en el momento crítico de despedirse de la vida. Tiempo habrá, supongo, para estudiar las causas de esta tragedia tan descomunal y tratar por todos los medios de evitarla en el futuro.

Como escritor y como hombre de letras, ¿comparte esa idea que se ha generalizado de que los escritores y escritoras están acostumbrados a estar aislados en sus casas o en sus mundos interiores cada vez que se enfrentan a una nueva obra? ¿Cree que eso les ha ayudado a sobrellevar el aislamiento?

El aislamiento, qué duda cabe, forma parte del quehacer del escritor y, por tanto, es probable que dicha práctica les haya ayudado a muchos a sobrellevar el aislamiento con menos aturdimiento y ansiedad que a la mayoría de las personas. Pero nunca me atrevería a generalizar ni a pontificar sobre este asunto ni sobre cualquier otro. Algunos, hombres y mujeres, me han comunicado que estaban salvando la papeleta sin mayores complicaciones; otros, en cambio, lo han pasado tan mal como cualquier hijo de vecino. Creo que el temperamento es un factor clave en la trayectoria de cada persona y suele ser decisivo, verdadera prueba de fuego, en las circunstancias más adversas.

\section{¿Cómo ha sido su rutina en estas semanas? ¿Algún libro especial que haya leído? ¿Al- gún título para recomendar?}

En buena medida ya he contestado antes a su pregunta. Además de los paseos por el jardín, realizados con horario y disciplina casi castrense, he dedicado muchas horas del día a leer, escribir, escuchar música, ver cine... y mantener el contacto con los seres queridos. He echado muy de menos, eso sí, la compañía, alegría y achuches habituales de mis cuatro nietos, que he suplido con videoconferencias diarias en el caso de los dos mayores, nacidos y residentes en Viena, y mediante conversaciones desde la ventana con los navarros, convecinos nuestros. Y, por descontado, he seguido con escrupulosidad el calendario clínico de sesiones de quimio y otras pruebas en el CHN. Don Cáncer, qué le vamos a hacer, no sabe nada de vacaciones ni de estados de alarma; tampoco, de confinamiento ni de desescalada, vocablo espantoso.

El grueso de mis lecturas ha consistido en indagar, una vez más, en los clásicos, sobre todo en los grecolatinos: poetas, dramaturgos, narradores, filósofos e historiadores. Sus textos, siempre hospitalarios, los he sentido más vigentes y actuales que la prensa del día. Como decía el novelista italiano Italo Calvino, releer a un clásico, dadas sus 
inagotables virtualidades, es como acercase a él por primera vez. Es difícil explicar el inmenso goce sentido estos días tan inciertos, casi de pesadilla social, al sumergirme en los universos de La Ilíada y La Odisea de Homero, en los grandes trágicos griegos, en ciertos diálogos de Platón y en las narraciones históricas de Tucídides y Jenofonte. Adentrarme en los versos de Catulo, Virgilio, Horacio, Propercio, Juvenal y Marcial me ha permitido descubrir a cada paso un manantial de sabiduría y belleza. Y lo mismo puedo afirmar de la prosa de Cicerón, Julio César y Salustio.

Recomendar a alguien un libro implica conocer su personalidad, modos de vida, preferencias estéticas... No obstante, sugiero la lectura de Sobre la amistad, de Cicerón, y algún ensayo de Séneca: Sobre la felicidad, Sobre la brevedad de la vida y Epístolas morales a Lucilio, que ahondan en las dimensiones esenciales de la condición humana, esas que, engullidos por la vorágine de la vida diaria, tan rápida como superficial, desatendemos con demasiada frecuencia por falta de serenidad y quién sabe si tal vez por miedo a enfrentarnos a los grandes enigmas de nuestra propia vida.

Hace un año, el 4 de mayo de 2019, estaba en un marco bien diferente, recibiendo el Premio Príncipe de Viana de la Cultura en Viana, un premio que llegó como reconocimiento a toda una trayectoria, a toda una vida dedicada a la cultura, a la literatura y a la educación, como docente, investigador, divulgador y promotor cultural, como escritor, como lector... ¿Qué recuerdos tiene de ese día en el que dedicó el premio con un bonito discurso a su padre y a su pueblo y a la universidad de la vida?

Recuerdo esa jornada con emoción al ver reunidos a todos mis seres queridos: familia, amigos, colegas y una nutrida representación de la sociedad civil navarra. Quien estuvo más presente fue, paradójicamente, mi padre, Francisco Yerro Ona, fallecido hace treinta y cinco años, cuyo ejemplo de vida, unido al de mi madre, Blanca, y mi abuela paterna, Javiera Ona, desde la infancia fue decisivo en mi formación, en mi forma de ver el mundo, en mi relación con los demás. En su persona quise homenajear a miles y aun millones de personas anónimas, humildes, que supieron sobreponerse de manera abnegada y ejemplar a unas circunstancias de extrema dureza, como fueron la Guerra Civil y la negra posguerra, para ofrecer a sus descendientes, con suma abnegación y dignidad, un porvenir más esperanzador que el suyo. Mi carta-discurso trató de saldar una deuda de gratitud contraída con mi padre y también con el pueblo de Lerín, mi verdadera Universidad de Harvard, y con todas aquellas personas que me han venido acompañando y arropando a lo largo de mi vida personal y profesional.

¿Cómo vivió esos días del galardón? Se lo pregunto ahora que ha pasado un año y lo ha podido reposar. Supongo que es un momento emocionante, de gratitud y de reconocimiento.

Los viví con emoción y, por qué no decirlo, en ocasiones con cierta ansiedad, muy abrumado por la obligada y excesiva exposición en los medios. Recibir, entre otros muchos, mensajes muy cariñosos de exalumnos bachilleres y universitarios a los que había perdido la pista por completo hacía treinta o cuarenta años y felicitaciones de alcaldes, concejales y representantes de asociaciones culturales con los que traté durante mi paso 
por la Dirección General de Cultura-Institución Príncipe de Viana constituyó un regalo imprevisto e impagable. Mi padre, como buen labrador, solía decir: "Se cosecha lo que se siembra", frase que aquellos días me rondó a menudo por la cabeza. Siendo muy pequeño, tuve la fortuna de aprender de mis padres, de su ejemplo, las lecciones del deber, no solo del derecho, y de la gratitud, que de forma natural he practicado siempre. Si me permite una confidencia, le diré lo siguiente. Trabajando en el Departamento de Cultura, algunos funcionarios me manifestaron su sorpresa y alegría -algunos todavía me lo siguen recordando- por recibir de mi parte mensajes orales y manuscritos, privados y públicos, de felicitación y agradecimiento por su excelente labor al concluir un programa determinado. Por lo visto, era la primera vez que recibían tal clase de reconocimiento a pesar de llevar muchos años trabajando en la Administración. Para mí se trataba, sencillamente, de un acto de estricta justicia: todos los servicios públicos son el resultado de una tarea colectiva. Todavía continúo muy agradecido a la labor de muchos funcionarios y muy en particular de mis dos directores de servicio, José Ortega y Carlos Idoate, de valía humana y profesional excepcionales.

¿Recibir el Príncipe de Viana le ha cambiado en algo; le ha hecho reflexionar en una dirección diferente? ¿Siente que forma parte de una cierta élite de la cultura o por el contrario cree que es un paso más en su manera de entenderla, un aprendizaje nuevo?

No, no me ha cambiado en nada. Lo que sí vengo observando desde que recibí el premio es que algunas personas que no me conocen demasiado me miran con otros ojos, como si yo fuese un ser extraordinario. Y nada más lejos de la realidad. Continúo siendo el de siempre y, por tanto, actuando con la sencillez habitual, movido por los ideales de siempre en cualquiera de mis facetas vitales. Me sigo conformando con seguir mejorando un poco, solo un poco, mi entorno personal, laboral y social. Desconfío profundamente de quienes se consideran una élite de la cultura, sobre todo cuando esta se concibe en exclusiva en términos onanistas, como erudición autosuficiente o exhibicionista, o de mero espectáculo, no como una herramienta de transformación social. Si la cultura no sirve para implantar de veras los principios de libertad, sentido crítico, justicia, solidaridad, verdad, bondad y belleza, podemos prescindir de ella sin ninguna clase de miramientos. Si la cultura no fomenta el cultivo de las extraordinarias potencialidades humanas y se convierte en factor de cohesión social, sirve de bien poco, aunque las industrias culturales, muy importantes desde el punto de vista económico y por tanto necesitadas de apoyos, sigan su curso, perspectiva incierta durante y después de la pandemia causada por el Covid-19. Están obligadas, en muchos casos, a reinventarse si desean sobrevivir en medio de las limitaciones impuestas por la crisis sanitaria y sus secuelas.

¿Pesa cuando a uno le llaman referente, como usted lo es para los escritores navarros, teniendo en cuenta que fueron ellos quienes impulsaron su candidatura a través de la asociación?

Todavía no doy crédito a que la Asociación Navarra de Escritores-Nafar Idazleen Elkartea aprobara mi candidatura, sin mi conocimiento previo, en 2018. Más aún, que volviera a presentarla, contra mi voluntad, al año siguiente. Aun así, claro está, les estoy 
muy agradecido a sus asociados porque entendí su decisión como una prueba más de afecto. Lo de «referente» es un término que, aplicado a mi persona, me desconcierta. La Asociación sabrá explicar qué quisieron decir al otorgarme dicho calificativo. Puedo asegurar, eso sí, que he procurado estudiar con rigor sus obras, difundirlas en mis clases y en otros foros, y en no pocas ocasiones les he echado una mano asesorándoles y revisando sus textos en un diálogo cordial y amistoso. Durante muchos años me he dedicado a analizar y divulgar la obra de autores extranjeros y españoles de diversas épocas, pero creo que, como solía decirse en otros tiempos, «la caridad bien entendida empieza por los más próximos».

Me gustaría pedirle que recuerde quiénes han sido sus referentes en el mundo literario y en su trayectoria como investigador y docente.

Respeto y admiro muchísimo la persona y la obra de Pablo Antoñana, al que le profesé el afecto propio de un amigo. Sin salir de Navarra, los poetas Jesús Mauleón y Francisco Javier Irazoki saben cuánto les debo. La inmersión en las obras de Camilo José Cela, Gonzalo Torrente Ballester, Juan Goytisolo, Francisco Umbral, Francisco Brines y Eloy Sánchez Rosillo me ha deparado momentos inolvidables y muy provechosos. Michel de Montaigne y Miguel de Cervantes, además de Gustavo Flaubert, siguen brillando con luz propia y lo seguirán haciendo mientras alguien se acerque a sus ensayos y novelas, para mí casi insuperables.

Como investigador, debo a Fernando González Ollé, catedrático de Historia de la Lengua en la Universidad de Navarra, las primeras lecciones sobre cómo acercarse con rigor a un texto por sus múltiples valores: psicológicos, sociales, lingüísticos, literarios... Lo mismo podría decir de Pedro Correa, catedrático del Instituto de Bachillerato Príncipe de Viana de Pamplona y también profesor, excelente, de la misma Universidad. No tuve la fortuna de contarme entre los alumnos de Fernando Lázaro Carreter, pero creo haber aprendido bastante de las obras del que fuera director de la RAE sobre la técnica investigadora y de sus sugerencias didácticas para un profesor de literatura, en particular las relativas al comentario de textos. En idéntico pedestal coloco al catedrático de Literatura Española Moderna y Contemporánea Andrés Amorós, de la Universidad Complutense de Madrid. Todos ellos, y otros que no cito, han contribuido a que haya sido un profesor vocacional, a que las clases con bachilleres y universitarios -jóvenes y seniores- fueran para mí un regalo que me permitía compartir con mis alumnos mis conocimientos, mis dudas, mis inquietudes, mi sentido crítico, mi gusto por la lectura y la escritura.

Nos conocimos hace muchos años, en los 90, en sus primeros pasos por Acción Cultural y por la política cultural en la que desempeño después el cargo de director general. No fueron años fáciles. ¿Cómo resumiría su trayectoria en este terreno? Sus mejores momentos, sus logros, aquello de lo que se arrepiente, un reto sin alcanzar...

Ha pasado ya mucho tiempo desde entonces, teniendo en cuenta que salí del Gobierno a primeros de septiembre de 1999. Resumir la trayectoria de aquellos años o elaborar un balance de mi gestión creo que son tareas que, de hacerse, les corresponden a otros. Prefiero quedarme con algunos hechos aislados y con ciertas impresiones. 
Entre 1991 y 1999 hubo en Navarra cuatro gobiernos diferentes, incluido el Tripartito formado por PSN, CDN y EA, de solo un año de duración entre mediados de 1995 y 1996. Es de sobra conocido que este último acabó como el rosario de la aurora con la dimisión del presidente Javier Otano por la famosa cuenta en la banca suiza. Me tocó, pues, bregar en procelosas aguas políticas a las órdenes de cuatro consejeros distintos. El consejero Pedro Burillo, del PSN, me nombró director general de Cultura del Tripartito sin conocerme personalmente y después de yo haber trabajo cuatro años a las órdenes de Javier Marcotegui, consejero de UPN. Sin duda, un hecho inaudito en los anales de la política foral, hoy irrepetible. Gocé de la confianza de mis jefes, que a veces yo mismo juzgaba excesiva, y de una muy considerable libertad de acción. Elucubración al canto: parece ser que se estimó más la persona y su gestión que su militancia política, que nunca he tenido. Certeza: un Gobierno de UPN me despidió, y con poca caballerosidad por cierto, por «ser el mejor director general del Gobierno, pero no ser político», en palabras del presidente Miguel Sanz.

Ampliar la red de casas de cultura, mejorar la formación de los coordinadores culturales, consolidar y empezar el proceso de modernización del sistema bibliotecario tras la elaboración de un ambicioso plan estratégico, poner en marcha el programa de conciertos didácticos con la Orquesta Sinfónica de Navarra, el apoyo a muchas asociaciones culturales de la sociedad civil, la continuidad acrecentada del programa de restauraciones del patrimonio histórico-artístico... fueron acciones, que tras salvar no pocos escollos, me proporcionaron muchas satisfacciones. Lo mismo podría asegurar de la Fundación-Museo Jorge Oteiza, cuya puesta a punto, plagada de dificultades de toda índole, me hizo olvidar los muchos dolores de cabeza padecidos por su causa durante casi cuatro años. De todos modos, no deja de ser un crudo y sorprendente exponente de las prácticas políticas que en 1998 el Ministerio de Cultura otorgara a la Institución Príncipe de Viana el Premio Nacional de Restauración y Conservación de Bienes Culturales, área en la que la Institución se distinguió desde sus mismos orígenes en 1940, y que yo fuera destituido al año siguiente a las pocas semanas de hacerse entrega del galardón en el monasterio de Irache. «Por tu gestión en el área de restauración del patrimonio histórico-artístico de Navarra», me sopló al oído, meses más tarde, un gerifalte de UPN. Por lo visto, alguna de mis decisiones, siempre en cumplimiento de la ley, había pisado más de un callo en varios ayuntamientos gobernados por dicha formación política.

El momento más insólito fue el vivido fuera ya del Gobierno, el año 2000, el día de la inauguración de la casa de cultura de Los Arcos. El alcalde, José María Blasco, con el que entablé una buena amistad durante el largo período de gestación y ejecución de uno de sus sueños más preciados, tuvo la deferencia y aun el atrevimiento de invitarme al acto inaugural y el gesto inaudito de sentarme durante la comida en la mesa presidencial entre él mismo y la baronesa Carmen Thyssen-Bornemisza, que dio su nombre al nuevo equipamiento. Algunos dirigentes políticos no daban crédito a lo que sus ojos estaban observando.

La sustitución de Festivales de Navarra, centrados en exclusiva en Olite, por unos Festivales dispersos en la Comunidad Foral (Pamplona, Tudela, Estella, Sangüesa, Al- 
sasua, Elizondo...), la estudiamos muy a fondo y se basó en razones de orden meteorológico y económico dado el alto número de espectáculos suspendidos, a lo largo de su historia, a causa de la lluvia y las tormentas sobrevenidas a la vera del Castillo en las noches de agosto. Pasados los años, pienso que no fue una decisión acertada. De hecho, supuso la pérdida de la genuina identidad de los Festivales, ligados desde su origen a una sede inigualable, como viene ocurriendo en casi todos los festivales del mundo. La posterior implantación del Festival de Teatro de Olite, y con éxito, ratifica mi apreciación.

En ocho años de gestión cultural hay muchas cosas que se pudieron llevar a cabo o se pudieron realizar en mejores condiciones. Me quedo con dos, cuya ejecución desbordaba con mucho mis competencias, pero no por ello dejé de insistir una y otra vez, en vano, ante las instancias con mando en plaza foral. Me parecía y me sigue pareciendo injusto que en la Administración no se estimule ni gratifique el trabajo especialmente valioso de algunos funcionarios, cosa que sí ocurre en la empresa privada. Si todos los empleados de la misma categoría laboral cobran lo mismo y los cargos de máxima responsabilidad se adjudican con demasiada frecuencia por criterios de afinidad ideológico-política, no trae a cuenta implicarse en exceso en la dedicación al servicio público. Así y todo, fui testigo de que la mayoría de funcionarios cumplía con creces sus obligaciones. La cuestión, de hondo calado, afecta a la política general del personal de las administraciones públicas, reforma pregonada de continuo, pero a la que nadie quiere hincarle el diente de una vez por todas. También salí del Departamento de Cultura con una espina clavada que, tras darme la lata durante varios años, creí ingenuamente que estaba curada. En el verano de 1999, todo parecía indicar que el Gobierno, no solo el Departamento de Educación y Cultura, tenía decidida la ubicación de la nueva sede de la Biblioteca General de Navarra en el solar que actualmente ocupan los grandes almacenes de El Corte Inglés. Intereses económico-políticos de dudosa legalidad defendidos por el Ayuntamiento de la capital, a los que acabó sumándose el Gobierno de Navarra y hasta el Ministerio de Defensa, dieron al traste con las tortuosas gestiones emprendidas por mi predecesor en el cargo, Francisco Javier Zubiaur, y por mí mismo junto con la asesoría de un nutrido grupo de especialistas navarros y de diversas comunidades autónomas, además de técnicos del Ministerio de Cultura.

Mucho ha llovido desde entonces, todo ha cambiado, también la forma en que consumimos y generamos cultura y hasta el propio significado de la palabra. ¿Cuál es hoy su concepción de la cultura?

Mi forma de entender la cultura ya la he perfilado en una de mis respuestas anteriores. Quiero subrayar la importancia fundamental de las nuevas tecnologías en todos los ámbitos de la vida personal, familiar, laboral y social, también en el territorio de la cultura. Están favoreciendo su democratización en un grado inmenso, impensable hace tan solo unos pocos años. Ya sé que no es lo mismo visitar un museo o tocar con las propias manos un documento histórico en un archivo, asistir en directo a un concierto o a una representación teatral u operística, ver una película en compañía de los amigos en una sala, pisar un monumento histórico-artístico o recorrer las calles de una hermosa ciudad o de un pueblo pintoresco... que regocijarse con esas joyas del espíritu humano 
en una pantalla de ordenador o smartphone. Aun con todas las limitaciones que se quiera, se puede afirmar que las nuevas tecnologías permiten la existencia de una legión de verdaderos viajeros inmóviles de la cultura. Todo un privilegio al alcance de los países occidentales. Además, las nuevas tecnologías, que ponen en comunicación inmediata a todos los creadores y facilitan el intercambio de información y experiencias, son unas herramientas que les están abriendo unos horizontes casi ilimitados, en contenidos y formatos, con los que los jóvenes y no tan jóvenes sintonizan enseguida.

La distinción entre alta y baja cultura es un asunto que interesa más a los académicos que a la población en general, porque entre ambas existe una frontera muy frágil y permeable, mutuamente enriquecedora, como nos enseñó el sabio Umberto Eco. De ahí que con frecuencia verdaderas mamarrachadas se consideren obras culturales de mucho valor, cuando más bien habría que hablar en estos casos de esnobismo y mucho precio. Es cierto que el canon cultural y artístico va evolucionando a través de la historia, pero hay obras maestras de todas las artes y épocas que han pasado la prueba exigentísima del tiempo. Son las clásicas que siempre siguen iluminando -para imitarlas, homenajearlas, distorsionarlas o criticarlas- los permanentes afanes renovadores de músicos, escritores, pintores, escultores, arquitectos... Y pobres de aquellos creadores que mantengan una ingenua posición de adanismo, ignorando que, como decía Eugenio d'Ors, «Todo lo que no es tradición es plagio».

En este contexto tan confuso, la educación, reglada e informal, qué más da, deviene más que nunca un instrumento de primerísimo orden para distinguir, como antes decía, las voces de los ecos. Quiero subrayar el valor primordial de la enseñanza media o secundaria, hoy tan maltratada, por corresponder a una etapa decisiva en la formación y maduración de los alumnos, aquella en la que se decantan los gustos y preferencias, se vive con singular intensidad el presente y el futuro, y se forjan vocaciones de por vida. Pero me temo que los poderes públicos no creen demasiado en la cultura: más bien la temen o, en el peor y más frecuente de los casos, la desdeñan o la marginan dado su esencial fermento crítico.

Difícil momento el que vivimos para sostener esa idea de que «lo importante son las personas no las ideas» que usted citó hace un año en su discurso. La política parece que se olvida de su deber a lo público, a la sociedad, a los ciudadanos.

Quise recordar aquella frase de mi padre, pronunciada con la autoridad que le otorgaba su experiencia de vida: su condición de idealista combatiente voluntario, a los dieciocho años, en el bando nacional durante la Guerra Civil, su profunda decepción al observar el comportamiento del bando triunfador, las injustas condiciones de vida de la posguerra... Hoy da la impresión de que la sociedad, alentada y representada de modo muy principal por la clase política, se halla instalada en las trincheras en posiciones caracterizadas por el sectarismo, el dogmatismo, la intransigencia, la descalificación completa del adversario... Una buena parte de los políticos parece actuar más movida por el afán de recaudar votos a cualquier precio que por el bienestar de los ciudadanos. Si deshumanizamos al que no piensa como nosotros, el resultado será, lo está siendo ya en parte, devastador para la buena convivencia ciudadana, el basamento de toda sociedad 
democrática digna de tal nombre. Lo cual no supone desterrar, ni muchísimo menos, el debate, la confrontación de ideas y propuestas encaminadas al bien común, es decir, a la mejora de las condiciones de vida de los ciudadanos más débiles y vulnerables.

El mundo está revuelto, ¿no cree? ¿Cómo lo ve después de esta grave crisis en las que estamos inmersos y en la que la cultura será uno de los sectores más castigados seguro?

No tengo poderes de adivino, así que me limitaré a exponer algunas impresiones y deseos. Considero una locura inaudita e inaceptable que en las manos de personajes elegidos por sus conciudadanos como Trump o Bolsonaro, por citar solo los a mi juicio más relevantes, se halle el destino de millones de ciudadanos en sus países y, por extensión, en todo el mundo. En la actual geoestrategia mundial, resulta muy preocupante que las peleas de gallos de alto copete entre los presidentes de USA, China y Rusia sean capaces de poner a la humanidad patas arriba. Menos mal que el coronavirus, muy democrático él, a trancas y barrancas les ha rebajado un tanto los humos. Me gustaría que, en lugar de encerrarnos en el nido cada vez menos seguro de nuestras propias naciones, fuéramos capaces de arbitrar fórmulas políticas de cooperación globalizada mucho más eficientes que las auspiciadas hasta la fecha por la ONU y otros organismos internacionales. No lo verán mis ojos, seguro, pero Occidente solo sobrevivirá si es capaz de tratar en pie de igualdad, quiero decir de justicia, a los países del Tercer Mundo, a los países emergentes. Poner puertas al campo de la emigración representa una política condenada al fracaso si, regulada, no se establece sobre los cimientos de la solidaridad y la justicia social. El hambre y la injusticia en general no saben de fronteras, por mucho que durante la pandemia estemos asistiendo al lamentable espectáculo del egoísmo individualista del sálvese quien pueda, que contrasta con los ejemplos admirables de compasión, altruismo y solidaridad acreditados por muchos profesionales y voluntarios.

Cuando ya son millares los puestos de trabajo perdidos durante la crisis de la pandemia y la cifra será millonaria en meses posteriores, me temo que el sector de la cultura quede en buena medida relegado. Para colmo, las medidas preventivas de orden sanitario no favorecen la concentración de personas en salas de conciertos, cines, teatros, museos, estadios, etcétera. En este sentido, fueron muy elocuentes, por desalentadoras, las primeras declaraciones del ministro de Cultura, Rodríguez Uribes, ante las peticiones procedentes de su propia cofradía cultural. Sin embargo, sigo creyendo que la cultura de verdad a la que antes me refería, la transformadora, es más necesaria ahora que nunca precisamente por estar atravesando, y la que nos espera, un momento histórico de crisis personal y social muy honda, necesitada de faros muy potentes surgidos del campo de la ciencia, sí, y también del de las humanidades, tan denostadas o preteridas por el poder y tan invisibles y desconocidas para la mayoría de los ciudadanos.

Siempre se ha definido como un divulgador de la literatura navarra. Por sus manos han pasado muchos proyectos que me gustaría que recordase. ¿Lo sigue siendo?

Como le he indicado, en mis clases impartidas en diferentes niveles educativos siempre he incluido la lectura, el comentario y el debate de obras de autores navarros. En 
1990, mi colega y amigo Emilio Echavarren y yo mismo pusimos en marcha un programa denominado "Aproximación de la literatura navarra a los escolares», destinado a alumnos de EGB, FP y Bachillerato. Durante casi veinte años, muchos escritores de Navarra tuvieron la oportunidad de entablar en las aulas una relación directa y muy gratificante con miles de estudiantes que jamás habían visto de cerca a un escritor. De aquel programa surgieron no pocas vocaciones de escritores y, sobre todo, una consideración de la literatura no como un arte histórico, lejano y mitificado sino como el fruto del talento de unas personas normales y corrientes dotadas de unas habilidades especiales para captar la variedad de colores de la paleta de la vida y expresarla mediante la palabra. Fue una verdadera pena que un mandamás del Departamento de Educación, a la vista del éxito continuado y creciente del programa, decidiera liquidarlo por innecesario. Vivir para ver.

Estando en la Dirección General de Cultura, apoyé de manera decidida el muy solvente proyecto sobre historia literaria de Navarra, presentado por los profesores Ángel Raimundo Fernández González y Carlos Mata, de la Universidad de Navarra, que pocos años más tarde se plasmaría en varias publicaciones de referencia sobre la materia. Fue una lástima que en aquellos momentos ningún investigador, profesor o crítico literario emprendiese la misma aventura referida a la literatura vasca, labor que Joxemiel Bidador plasmó por libre en las páginas de Diario de Noticias y en su muy meritoria obra Materiales para una historia de la literatura vasca en Navarra, que publicó Pamiela en 2004.

Hábleme de su biblioteca. Tiene miles de libros que según he leído ordena por épocas y nacionalidad del autor. No necesita un registro para recordar dónde está cada libro. Tiene que ser un lugar muy especial en su casa. ¿Recuerda algún título con especial cariño o admiración?

Mi biblioteca es fruto, cómo no, de mi variada curiosidad y de la acumulación de libros desde mi época de estudiante de bachillerato hasta la actualidad. Recuerdo sobre todo las primeras adquisiciones en librerías pamplonesas como la Universitaria, Manantial y, de modo especial, Andrómeda y El Parnasillo, regentadas estas dos últimas por Javier López de Muniáin, un librero de la vieja escuela, culto, sensible, cercano, asesor de los clientes. Después me acerqué a otras librerías locales, nacionales y europeas aprovechando los viajes de trabajo o de placer. De momento puedo recordar la ubicación de todas las obras, no sé qué pasará en el futuro inmediato. A veces, eso sí, me asaltan los versos del poeta Antonio Martínez Sarrión, que siento como propios, dedicados precisamente a los libros de su biblioteca: «Habrá de pasar tiempo, / dejadme imaginarlo, / hasta que se acostumbren a otras manos: / ojalá no sean ásperas con ellos». Mi biblioteca, todas las bibliotecas, son para mí como verdaderos santuarios en los que, recordando a Quevedo, «Vivo en conversación con los difuntos, / y escucho con mis ojos a los muertos». Es difícil expresar con más concisión y paradójica belleza los lazos de amistad surgidos de la permanente conversación de un lector apasionado con los autores de sus libros preferidos.

Muchas obras de la famosa colección Austral y de la muy popular colección RTV, editada en colaboración con Salvat e iniciada con La tía Tula de Unamuno (los prime- 
ros libros costaban 25 pesetas), poseen para mí una significación muy especial, aunque la calidad del papel y la tipografía dejen mucho que desear para el gusto de un lector actual. Fueron las primeras compras sistemáticas. La obra a la que le tengo más apego es, con mucho, una edición madrileña del Quijote fechada en 1904, publicada por Saturnino Calleja en la Biblioteca Perla, ilustrada con 316 grabados. Su valor sentimental reside en que fue el primer Quijote que leí, trabajosamente, a los diez u once años, y el hecho de que formara parte de la pequeña biblioteca, unas doscientas obras, que me regaló la citada abuela Javiera.

\section{Como buen conocedor de literatura, ¿algún título para un momento como este?}

El Decamerón, de Giovanni Boccaccio, escrito en circunstancias parecidas a las actuales de pandemia y fuente inagotable de placer. Y el Quijote: en la negra perspectiva que se nos avecina, todos los ciudadanos vamos a necesitar el realismo práctico de Sancho Panza y el idealismo altruista de don Quijote, que no son incompatibles entre sí, sino, todo lo contrario, dimensiones esenciales y complementarias de la condición humana.

\section{CUESTIONARIO BREVE}

- El último libro que ha leído: Como la sombra que se va, de Antonio Muñoz Molina, y Medea, de Eurípides.

- Su película: El Padrino II.

- Su obra de cabecera: La Biblia (Antiguo Testamento) y Madame Bovary, de Gustave Flaubert.

- Un autor imprescindible: William Shakespeare.

- Lo mejor que le ha dado la literatura: Conocerme mejor a mí mismo y a los demás y, en consecuencia, ser más comprensivo y solidario.

- Su peor experiencia: Una amistad traicionada.

- Lo que nunca repetiría: Acceder a un puesto de responsabilidad política.

- Su mayor acierto: Disfrutar apasionadamente, pero sin estridencias, con todas mis actividades privadas, profesionales y de voluntariado.

- Un sueño cumplido: Verme rodeado por una familia que me quiere y a la que quiero.

- Una meta todavía por alcanzar: Contribuir más a la justa valoración social de los ancianos.

- Un consejo a quien empieza: Trabajo, constancia y discreción.

- Alguna frase que le marcó: «No olvides nunca, Tomás, de dónde has salido» (mi padre, cuando yo tenía doce años).

- Alguna anécdota que merece no olvidarse... y alguna para no recordar. En el aeropuerto de Noáin, el año 1998, el saludo militar de un cabo y un número de la Guardia Civil al confundirme con el ministro de Cultura (que a la sazón era Esperanza Aguirre) mientras esperaba a Josep Carreras, presidente de honor del jurado del Concurso Internacional de Canto Julián Gayarre. Mejor olvidar la rotura del pantalón del traje, por la popa, al terminar una conferencia sobre Amado Alonso en la Universidad de Sevilla, cuyo Ayuntamiento, presidido por Soledad Becerril, rotuló una calle con el 
nombre del ilustre filólogo, profesor y crítico literario lerinés. Menos mal que me tapó la retaguardia una diligente profesora.

- ¿Cómo se lleva con las nuevas tecnologías? ¿Y con el ebook? Me defiendo sin especiales dificultades, pero no pertenezco a ninguna red social. Tengo mucho que aprender en este terreno, en el que mi esposa y mis hijas me dan sopas con honda. El ebook lo utilizo de viaje en determinadas ocasiones. Sigo prefiriendo el libro en formato de papel, que se puede tocar y oler.

\section{CURRICULUM}

Tomás Yerro Villanueva (Lerín, 1950) es licenciado en Filología Románica por la Universidad de Navarra, ha sido catedrático de Bachillerato de Lengua y Literatura Españolas y profesor de la Universidad de Navarra, de la Universidad Pública de Navarra, de la Universidad Nacional de Educación a Distancia y de la Universidad para Mayores Francisco Induráin.

Columnista habitual en la prensa navarra, ha publicado en diversas revistas científicas como Cuadernos de pedagogía, Revista de filología y su didáctica o Cuadernos de Etnología y Etnografía de Navarra. Dirigió la revista de poesía Río Arga, en la cual ha publicado con frecuencia, y fue el fundador y primer director de Ítaca, revista de educación editada por el Ministerio de Educación y Cultura, así como miembro del comité editorial de Cuadernos gerontológicos, editados por la Sociedad Navarra de Geriatría y Gerontología. Tomás Yerro participó también en la creación del Ateneo Navarro/Nafar Ateneoa y es miembro del patronato de la Fundación Amado Alonso. Fue director del Servicio de Acción Cultural del Gobierno de Navarra entre 1991 y 1995 y director general de Cultura entre 1995 y 1999.

Entre otras obras, es autor de «Aspectos técnicos y estructurales de la novela española actual» (1977), Río Arga, revista poética navarra: estudio y antología (con Charo Fuentes, 1988), Escritores navarros actuales: antología (coord. 1990), Narrativa española actual 1993-1997 (1998), Por la senda del Quijote (coord. 2005), Amado Alonso: el español de las dos orillas (coord. 2014). Ha participado en multitud de obras colectivas, $\mathrm{y}$ ha escrito el prólogo o estudio introductorio de numerosas publicaciones de otros autores. 